\title{
The future for personal doctoring
}

A continuing patient-doctor relationship has achieved the status of a core value and feature of primary care. ${ }^{1}$ In this issue of the $B J G P$, two papers by Salisbury et $a l^{2}$ and Ridd et $a{ }^{3}$ add to the large body of primary care research seeking to improve the definition and measurement of the continuing patient-doctor relationship. The aim is to understand and defend it as a core feature. It has been under pressure as primary health care moves away from autonomous single-handed practices to multidisciplinary group practices with common accountability to central authority.

For primary care and family medicine the continuing patient-doctor relationship has been subsumed under the broader concept of continuity of care. ${ }^{4}$ Clinicians from other health disciplines recognise the importance of the relationship with the patient but use the term 'continuity of care' to refer to the delivery of services in a coordinated and timely manner by more than one health professional. Salisbury and colleagues call this coordinated care, as would most primary care clinicians. Both Salisbury et al and Ridd et al use the label 'longitudinal continuity' to describe the primary care model of continuity of care, a tribute to Barbara Starfield who proposed this term to distinguish it from that of continuity of care used in other disciplines. ${ }^{5}$

Ridd et al synthesize what qualitative research tells us about the nature of the patient-doctor relationship, where the regularity of good experiences with the doctor over time leads to increasing depths of knowledge, trust, loyalty and regard. An article that appeared in this journal in November confirms that these qualities do indeed require time and good rapport. ${ }^{6}$ With good measures of such constructs we may be able to quantify the contribution that patient-doctor relationships make to quality of care and good health outcomes. Robust measures have been developed for the dimension of knowledge ${ }^{7-9}$ and for trust ${ }^{7}$ and these have been linked to outcomes such as increased satisfaction ${ }^{10,11}$ perceived smoothness in seeking care, ${ }^{12}$ better preventive care coverage ${ }^{13}$ and more appropriate application of wait-and-see use of antibiotics. ${ }^{14}$ Measures of loyalty and regard are either non-existent or in development.

Salisbury et al approach the issue from a more quantitative perspective, providing an extensive overview of the different ways that 'longitudinal continuity' can be inferred from patterns of clinical encounters over time. Although some have questioned whether these measures truly capture the nature of longitudinal continuity as described by Ridd et al, they are still used because they can be obtained from routinely available data. Researchers are able to track the impact of healthcare changes on concentration of care in a specific doctor or team. Much of the evidence that has accrued on the benefits of the continuing patient-doctor relationship is based on such quantitative measures of healthcare patterns. ${ }^{5,15,16}$

Salisbury et al's paper is particularly relevant because even strong defenders of primary care continuity have argued that there is a necessary trade-off between being seen promptly and seeing one's own doctor. ${ }^{5,17}$ Salisbury and colleagues found that the introduction of an Advanced Access system did not lead to statistically significant differences in measures of concentration of care. However, there was a consistent tendency toward decreased concentration in Advanced Access practices. Although not statistically significant in a study with a large sample, the consistency of the tendency across different measures combined with a priori hypotheses that continuity would be affected, leaves one with a niggling suspicion that there is more to the story, such as a specific group of patients that are particularly affected. The main study also showed that access gains were also very modest with the introduction of the Advanced Access system. ${ }^{18}$ Research in Canada found that patient perceptions of their doctor's knowledge of them decreased when the doctor had an access-oriented practice style ${ }^{19}$ and there continues to be a tension between ensuring longitudinal continuity and prompt access. ${ }^{20}$ In contexts, such as Canada, where there is more room for improvement in access ${ }^{21,22}$ the rush to improve timeliness may be offset by larger losses in continuity than those observed by Salisbury and colleagues.

All systems in industrialised countries face the challenge of retaining the benefits of a continuing patient-doctor relationship in a context of team care. Starfield shows that the benefits of concentrating care in a clinical site are generally lower than in a specific doctor, unless the provider team shares the same approach and philosophy of care. ${ }^{5}$ Safran proposed that the team needed to be 'visible' to patients and not just to the clinicians. ${ }^{23}$ However, a recent study from that research group ${ }^{24}$ shows that it is less the visibility of the team than the quality of the patient-team relationship, as measured by the degree to which team members coordinated care with the patient's doctor, explained things clearly, and knew them as a person. While these indicators only partially capture the dimensions of knowledge, trust, loyalty, and regard, they suggest that depth of relationship can apply to a team as well as to a specific doctor. However, the study also confirms previous findings showing that patients who always consult the same doctor have higher assessments of all dimensions of primary care than those who do not.

What implications can be drawn from these articles about how services are organised? The Salisbury et al article provides a measure of reassurance that, regardless of access-focused innovations, the vast majority of patients obtain care from their provider of choice when it is important to them. Ridd et al point out that the patient's capacity to exercise this choice ensures a high quality of patient-doctor relationship as opposed to one that is merely endured. In the face of pressure to ensure prompt access, it is important to retain sufficient organisational flexibility so that patients can choose between promptness of care and seeing a preferred provider according to their specific needs at the time. Savvy patients find ways to ensure this choice, but some - such as those from lower educational achievement or recent 
immigrants - are less able to advocate for their preferences and will be more dependent on the way that the services are organised. ${ }^{25,26}$ Again, this is a whole team effort. Ridd et al refer to reception staff contributing to good patient-doctor encounters. More than simply assuring a 'positive frame of mind' for the clinical encounter, the reception staff can function as an extension of the relationship with the doctor. This requires that the reception staff are conceived as part of the care team and internalise the practice philosophy as much as the clinicians do.

Despite the large body of evidence supporting the importance of concentrating care in known and trusted providers, the continuing patient-doctor relationship still needs to be defended both within primary care and the wider health system. It requires personal and professional commitment by doctors to patients and to the rest of the care team, but it can easily be eroded in a context of constant system change. Research that brings together the qualitative dimensions of the relationship with quantitative measures of healthcare patterns may provide insight whether there is a critical zone of concentration of care at which the therapeutic benefits of continuity are compromised.

\section{Jeannie Haggerty,}

Associate Professor, Department of Community Health Sciences and Family Medecine, University of Sherbrooke, Longueuil, Québec, Canada.

\section{REFERENCES}

1. McWhinney IR. Primary care: core values. Core values in a changing world. BMJ 1998; 316: 1807-1809.
2. Salisbury C, Sampson F, Ridd M, Montgomery AA. How should continuity of care in primary health care be assessed? Br J Gen Pract 2009; 59(561): 276-282.

3. Ridd M, Shaw A, Lewis G, Salisbury C. the patient-doctor relationship: a synthesis of the qualitative literature in patients' perspectives. Br J Gen Pract 2009; 59(561): 268-275.

4. Haggerty JL, Reid RJ, Freeman GK, et al. Continuity of care: a multidisciplinary review. BMJ 2003; 327: 1219-1221.

5. Starfield B. Primary care: balancing health needs, services, and technology. New York: Oxford University Press; 1998

6. Tarrant C, Colman AM, Stokes T. Past experience, 'shadow of the future', and patient trust: a cross-sectional survey. Br J Gen Pract 2008; 58: 780-783, i-vi.

7. Safran DG, Kosinski J, Tarlov AR, et al. The primary care assessment survey: test of data quality and measurement performance. Med Care 1998; 36(5): 728-739.

8. Flocke, S. Measuring attributes of primary care: development of a new instrument. J Fam Pract 1997; 45(1): 64-74.

9. Shi L, Starfield B, Xu J. Validating the adult primary care assessment tool. J Fam Pract 2001; 50:

http://www.jponline.com/Pages.asp?AID=2157\&issue= ebruary 2001\&UID $=($ accessed 12 Mar 2009).

10. Safran DG, Taira DA, Rogers WH, et al. Linking primary care performance to outcomes of care. J Fam Pract 1998; 47:213-220.

11. Flocke SA, Miller WL, Crabtree BF. Relationships between physician practice style, patient satisfaction, and attributes of primary care. J Fam Pract 2002; 51: 835-840.

12. Parchman ML, Noel PH, Lee S. Primary care attributes, health care system hassles, and chronic illness. Med Care 2005; 43: 1123-1129.

13. Flocke S, Stange KC, Zyzanski SJ. The association of attributes of primary care with the delivery of clinical preventive services. Med Care 1998; 36(Suppl 8): AS21-AS30.

14. Hjortdahl P. The influence of general practitioners' knowledge about their patients on the clinical decisionmaking process. Scand J Prim Health Care. 1992; 10: 290-294

15. Wasson JH, Sauvigne AE, Mogielnicki P, et al. Continuity of outpatient medical care in elderly men: A randomized trial. JAMA 1984; 252(17): 2413-2417.

16. Becker MH, Drachman RH, Kirscht JP. A field experiment to evaluate various outcomes of continuity of physician care. Am J Public Health 1974; 64: 1062-1070.

17. Freeman GK, Richards SC. Is personal continuity of care compatible with free choice of doctor? Patients' views on seeing the same doctor. Br J Gen Pract 1993; 43: 493-497.

18. Salisbury C, Montgomery AA, Simons L et al. Impact of
Advanced Access on access, workload, and continuity: controlled before-and-after and simulated-patient study. Br J Gen Pract 2007; 57: 608-614.

19. Haggerty J, Pineault R, Beaulieu M-D et al. Practice features associated with patient-reported accessibility, continuity and coordination of primary health care. Ann Fam Med 2008; 6: 116-123.

20. Pineault R, Levesque, J-F, Roberge D, et al. L'accessibilité et la continuité des services de santé: une étude sur la première ligne au Québec [Accessibility and continuity of health services: a study on primary health care in Quebec].http://www.inspq.qc.ca/pdf/publications/ 777_ServicesPremLignes.pdf (accessed 12 Mar 2009).

21. Schoen C, Osborn R, Huynh PT et al. Primary care and health system performance: adults' experiences in five countries. Health Aff (Millwood) 2004; Suppl Web Exclusives: W4-487-503.

22. Haggerty JL, Pineault R, Beaulieu M-D et al. Room for improvement: patient experience of primary care in Quebec prior to major reforms. Can Fam Physician 2007; 53: 1056-1057.

23. Safran DG. Defining the future of primary care: what can we learn from patients? Ann Intern Med 2003; 138: 248-255.

24. Rodriguez HP, Rogers WH, Marshall RE, Safran DG Multidisciplinary primary care teams: effects on the quality of clinician-patient interactions and organizational features of care. Med Care 2007; 45: 19-27.

25. Baker R, Boulton M, Windridge K, et al. Interpersonal continuity of care: a cross-sectional survey of primary care patients' preferences and their experiences. $\mathrm{BrJ} \mathrm{Gen}$ Pract 2007; 57: 283-289.

26. Boulton M, Tarrant C, Windridge K, Baker R, Freeman GK. How are different types of continuity achieved? A mixed methods longitudinal study. Br J Gen Pract 2006; 56: 749-755.

DOI: 10.3399/bjgp09X420275

ADDRESS FOR CORRESPONDENCE

\section{Jeannie Haggerty}

Centre de recherche, Hôpital Charles

LeMoyne, 3021, boul. Taschereau

Greenfield Park, QC J4V $2 \mathrm{H} 1$

E-mail: Jeannie.Haggerty@USherbrooke.ca

\section{Tired all the time:}

can new research on fatigue help clinicians?

Over $10 \%$ of patients attending primary care clinics describe at least one month of substantial fatigue. ${ }^{1}$ Despite its prevalence, many clinicians feel uncertain or dissatisfied with the level of care they are able to provide patients with persistent fatigue. ${ }^{2}$ These anxieties are not without basis; up to twothirds of patients with chronic fatigue report being dissatisfied with the quality of care they receive. ${ }^{3}$ GPs will tend to stereotype patients with chronic fatigue as having certain undesirable traits and will feel a sense of hopelessness regarding treatment options. ${ }^{4}$ However, there is now an emerging body of research evidence which should provide GPs with a greater sense of certainty regarding their management decisions. Incorporating this evidence base into clinical practice should allow clinicians to feel less helpless, and will hopefully result in improved outcomes for patients suffering from the debilitating effects of fatigue.

One of the main anxieties when managing a complaint of fatigue is how to begin and when to end investigations aimed at identifying any underlying physical disease. This difficulty stems from fatigue being a 